\title{
Exploring the Value of Understanding Society for Neighbourhood Effects Analyses
}

\section{Social and Economic History}

\author{
Gundi Knies \\ Institute for Social and Economic Research (ISER), University of Essex, \\ Colchester, UK \\ gknies@essex.ac.uk
}

\begin{abstract}
Understanding Society is a large representative household panel study for the U K. The study follows the same 40,00o households over time, beginning in 2009 and providing a detailed picture of how people's lives are changing. One of the many innovative features of Understanding Society is that a great deal of information about neighbourhoods can be used alongside the individual and household-level information collected in the study, making it a useful study for neighbourhood effects analyses. In this paper the author explores four Understanding Society data products, based on four different types of rural-urban neighbourhood classifications, to throw light on how much heterogeneity in neighbourhood contexts is captured in the first waves of Understanding Society, including change in neighbourhood contexts.
\end{abstract}

\section{Keywords}

neighbourhoods - quantitative analysis - household panel study - record linkage panel data analysis - geo-marketing

- $\quad$ Related data set "Understanding Society: Waves 1-6, 2009-2015" with DOI http://dx.doi.org/10.5255/UKDA-SN-6614-7 in repository "UK Data Service".

- $\quad$ See the showcase of the data in the Exhibit of Datasets: http://dansdatajournal.nl/rdp/dsdoc.html?id=knies2017 


\section{Introduction}

The idea that where people live can have an effect on their life chances over and above the effect of their individual characteristics has been the focus of much scientific inquiry across disciplines since the 1990s (Dietz, 2002; Friedrichs, Galster, \& Musterd, 2003; Galster, 2008). Neighbourhoods are places where people interact with one another, offering opportunities for learning from peers and role models but also placing limits on behaviours and aspirations; they provide access to services such as schools, shops and workplaces. Various socio-economic outcomes have been suggested to be influenced by where people live: employment, poverty and receipt of income support (Culliney, 2016; Musterd \& Andersson, 2006; Plum \& Knies, 2015), health (Propper et al., 2005), schooling (Burgess, Gardiner, \& Propper, 2006; Overman, 2002) and life satisfaction as a catch-all measure of well-being (Knies, Burgess, \& Propper, 2008; Knies, Nandi, \& Platt, 2016; Shields, Price, \& Wooden, 2009).

Longitudinal studies that follow individuals and track stability and change in different types of neighbourhoods are important vehicles in providing evidence of neighbourhood effects. Understanding Society, the UK Household Longitudinal Study (UKHLS) is the largest household panel study in the world, following the same approximately 100,000 individuals (at the first round of annual interviews) over time. It is a multi-topic, multipurpose study that not only provides large numbers of cases with particular characteristics salient to researchers interested in neighbourhood effects (such as unemployed people, teenagers or ethnic minorities) but also asks participants about many aspects of life that have been linked to neighbourhood effects. A lesser-known feature of the data is that it is possible to obtain access to objective qualitative information about the Study members' neighbourhoods, and to official geographical identifiers that allow record linkage with official social indicators about the neighbourhoods thereby opening up numerous avenues for new neighbourhood effects research.

\section{Context}

Understanding Society is the latest addition to the U K's collection of large-scale longitudinal studies. The household panel study is representative (subject to weighting) for each country and region of the $\mathrm{UK}$, and for areas of different population density within them. It started in 2009 with around 26,000 private households; in 2010 around 8,00o households who were previously interviewed as part of the British Household Panel Survey (B HPS) were added (University 
of Essex, 2010). The Study includes a boost sample of minority ethnic groups making it a unique resource for tracking change in the circumstances of minorities whose socio-economic disadvantage and residential segregation have been the focus of much neighbourhood research.

Interviews take place with all individuals aged 10 or older in responding households. The Study collects a wealth of information relating to the respondents' economic and social circumstances, their values and attitudes, and provides a detailed picture about how people's life circumstances change year on year. For example, Lynn and Knies (2015, p. 131) reported that from one wave to the next and over each of the first five waves, the Study has captured more than 1,800 transitions into employment, more than 600 transitions into selfemployment, and more than 1,60o transitions into unemployment.

The Study members' neighbourhood contexts and changes therein have not been reported. This would be an important first step in establishing the Study's research potential for neighbourhood effects research.

\section{Aims}

The standard end-user licence (public use) version of Understanding Society data, accessed via the U $\mathrm{k}$ Data Service, includes some higher-level geographical information (i.e., country, region, a coarse indicator of urbanity, respondent's neighbourhood perceptions). Analysts can explore raw frequencies in the online dataset documentation. By contrast, access to mid- or low-level geographical information is granted only to approved researchers and projects via a Special License (SL). Overall, the data series includes seven SL products that provide valuable qualitative information about the Study members' areas, and a further 11 products that allow linkage of geographically coded information. Applying for SL access presents a (low) hurdle to access, and linking data requires some specialist skills. The aim of this data paper is to compare and promote the neighbourhood information-enriched datasets and to provide key statistics about four resources available through SL to help potential analysts make a better-informed decision about applying for access.

\section{Methods}

We used data from the first five waves of Understanding Society (University of Essex. Institute for Social and Economic Research, 2015a), and linked it with information from four related data products that provide qualitative 


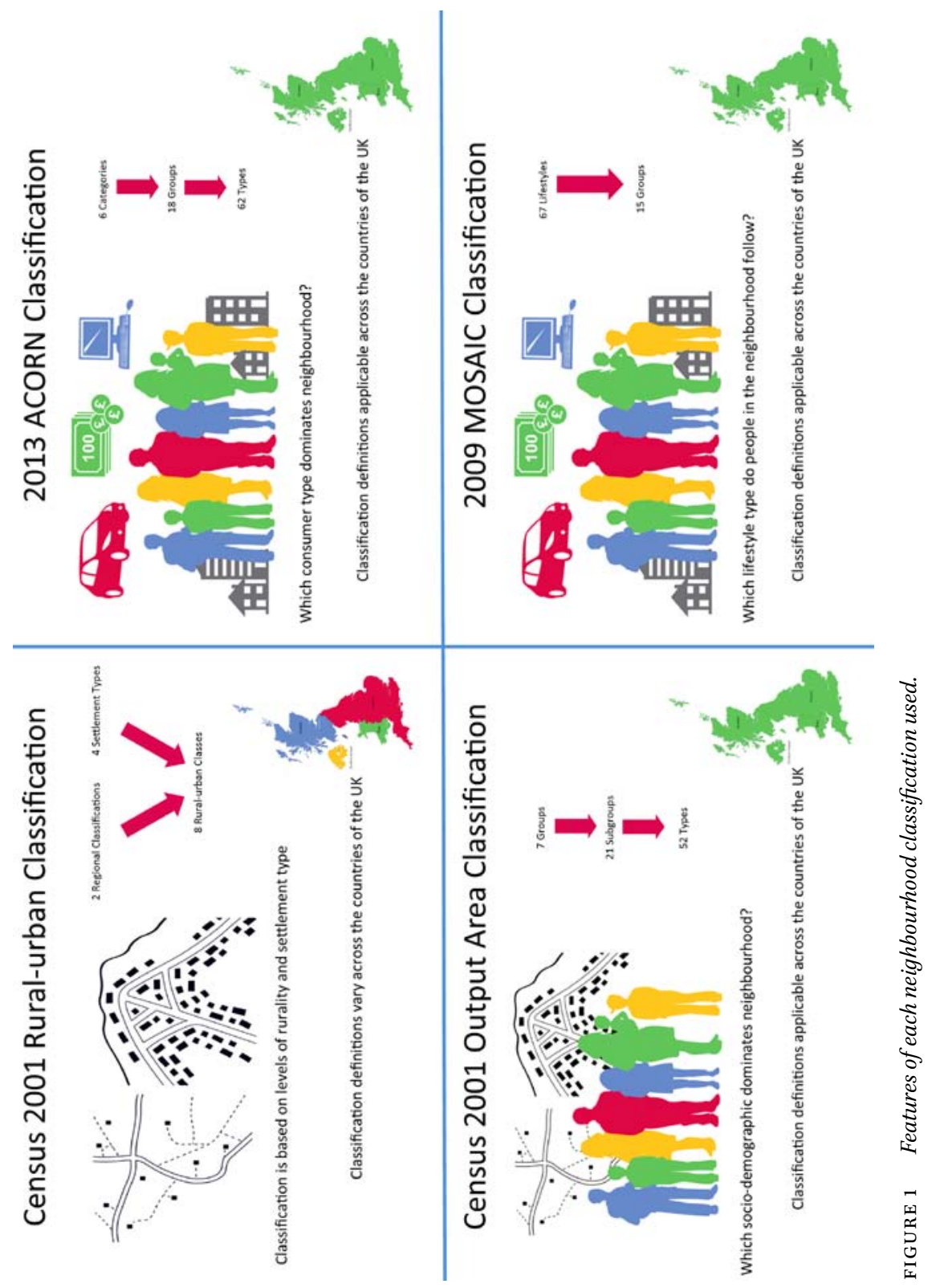


information about the types of neighbourhood people live in. The four neighbourhood classifications used are:

- 2001 Census Rural-urban classification

- 2001 Census Output Area Classification (OAC)

- ACORN 2013 classification

- MOSAIC UK 2009 classification

\subsection{The Neighbourhood Classifications}

Figure 1 sets out the distinctive features of each neighbourhood classification used in this paper.

The 2001 Census 'Rural-urban classification' is produced by the Office for National Statistics (ONS) on the basis of the 2001 Census and provides information about the rurality of very small Census areas (Office for National Statistics, 2016b). The definition adopts a settlement-based approach, comprising 4 settlement types, assigned to either a 'sparse' or 'less sparse' regional setting to give 8 classes of output areas.

The 2001 Census Output Area Classification (OAC) is another classification produced by the ons that draws on socio-economic and consumption information collected in the Census and allows for greater granularity in urban settings. It provides $5^{2}$ types overall which can be aggregated to 7 or 21 groups (Office for National Statistics, 2016a). An additional advantage of the classification is that it is comparable across the countries of the UK.

An alternative segmentation classification, developed primarily for analysing consumer behaviour is the ACORN classification, produced by a geomarketing firm on the basis of commercial data, and updated annually (CACI Limited, 2014). The classification has 62 neighbourhood types which can be aggregated to 18 groups and six descriptive categories.

Finally, MOSAIC UK 2009 is a typology of consumers, produced on an annual basis using Census and other publically funded data as well as commercial data. The typology reports how many people in the areas are members of 67 resident lifestyle types overall (Experian Limited, 2009). As such, it is well placed to capture even the smallest changes in the neighbourhood composition over time. The lifestyle types can be aggregated to 15 groups.

These first three classifications have in common that they are already linked to Understanding Society and provide a static top-level description of the neighbourhood at a particular point in time. In combination with Understanding Society, they allow us to investigate the role of neighbourhood change for movers only. The fourth classification provides very detailed information for each neighbourhood and needs to be linked by analysts themselves using 
look-up codes available as part of Understanding Society. In combination with Understanding Society, the classification allows us to look at neighbourhood change for movers and non-movers alike.

Here we describe and compare response profiles across these neighbourhood classifications. We first describe neighbourhood contexts in the cross-section for Wave 1 . This is followed by an exploration of the longitudinal patterns in the data. All figures are based on unweighted data for responding adults (i.e., individuals aged 16 or above), which means the results are not representative for the population living in the Uk. For a detailed description of the sample design, see Knies (2015).

\section{Classification Comparisons}

\section{1. $\quad 2001$ Census Rural-Urban Classification}

Figure 2 and Table 1 report the number of adult respondents in Wave $1 .^{1}$ The classification varies across the countries of the UK, hence we report profiles by country.

It can be seen that around two-thirds of respondents in England and half of those in Wales and Scotland live in densely populated urban areas. The Study also includes more than more than 100 respondents in all but the "Hamlet and Isolated Dwelling less sparse" category in England.

However, with the bulk of the sample respondents living in (dense) urban areas, the Rural-urban classification does not pick up neighbourhood heterogeneity for most respondents. The OAC, ACORN and MOSAIC classifications provide more differentiated descriptions of neighbourhoods. Figure 2 shows for respondents who live in Rural-urban type 'Urban area-less sparse' (England and Wales only) that all categories of the respective other classifications are represented in the Understanding Society sample.

\section{2. $\quad 2001$ Census Output Area Classification (OAC)}

Table 2 shows that the 7 -category OAC splits respondents into three to four large and three to four smaller sections of similar size, but with variation across countries. For example, the multicultural community type has 8,902

1 Additional results for Waves 1-5 are available, DoI:10.5255/UKDA-SN-852682. Sample sizes in Scotland, Northern Ireland and Wales increased significantly in Wave 2 when the B н PS incorporated its boost samples for these countries. In the later waves, all area types have more than 100 respondents. The only exceptions are sparse urban areas in Wales, remote and very remote small towns in Scotland, and, in Wave 5 only, the Derry urban area in Northern Ireland. 


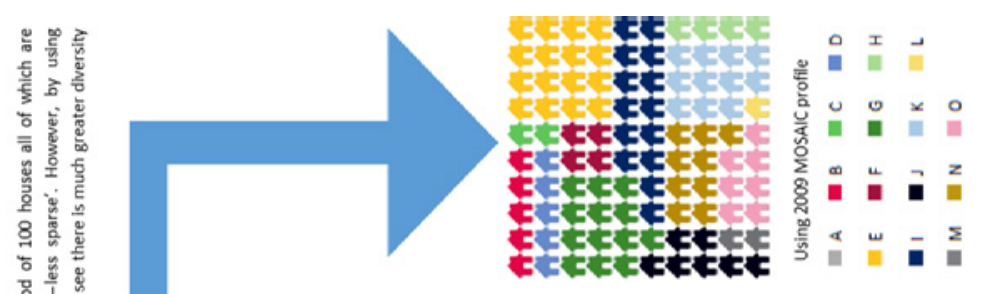

¿ุ

के

:

¿

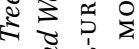

i

के

के क

\& 过 की n

¿

है छे प प्र

ई خो

D.

ن. అ

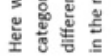
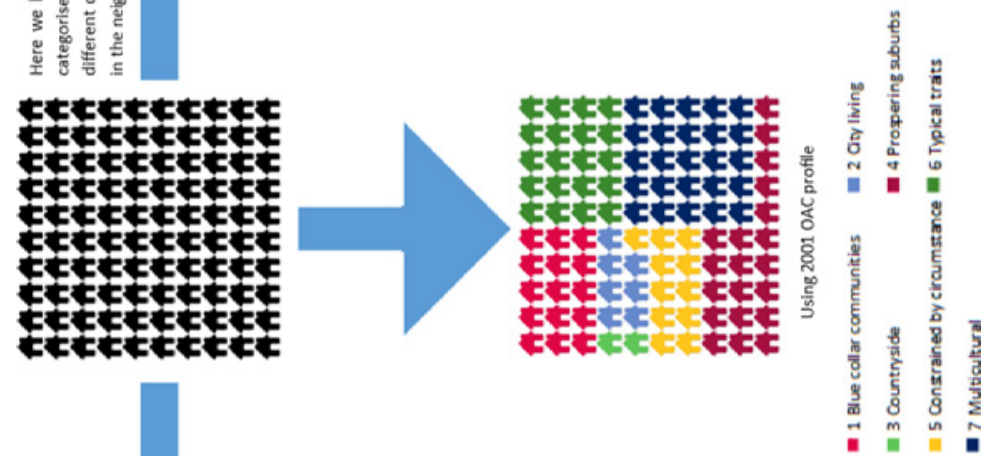

ฟ.ฐ

ई

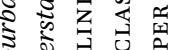

$\frac{1}{2}$ ¿

इ 5 된

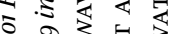

(1)

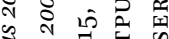

3ิ U

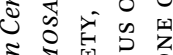

.ई

:

స్తે

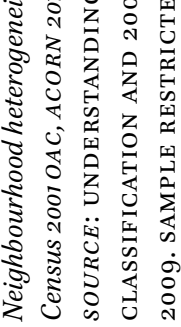

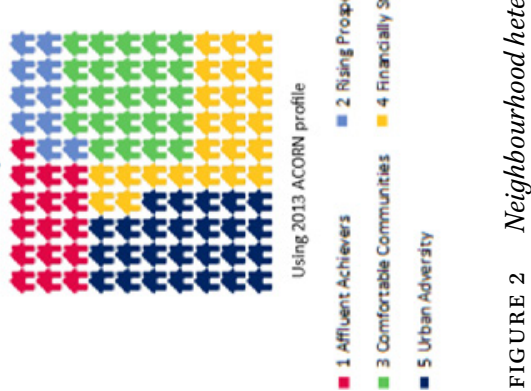


TABLE 1 Area profiles of respondents living in Rural-urban area type 'Urban area-less sparse, England and Wales only

Data set

Number of $\%$

observations

Census 2001 OAC

1 Blue collar communities

2 City living

3 Countryside

3,259

15

4 Prospering suburbs

5 Constrained by circumstances

6 Typical traits

7 Multicultural

Total

2013 ACORN

1 Affluent Achievers

2 Rising Prosperity

3 Comfortable Communities

4 Financially Stretched

5 Urban Adversity

6 Not Private Households

MOSAIC 2009 (dominant group)

A: Residents of isolated rural communities

B: Residents of small and mid-sized towns with strong local roots

C: Wealthy people living in the most sought-after neighbourhoods

D: Successful professionals living in suburban or semi-rural homes

E: Middle income families living in moderate suburban semis

F: Couples with young children in comfortable modern housing

G: Young, well-educated city dwellers

$\mathrm{H}$ : Couples and singles in small modern starter homes

I: Lower income workers in urban terraces in often diverse areas 
Data set

Number of $\%$

observations

$\mathrm{J}$ : Owner occupiers in older-style housing, typically in 759 ex-industrial areas

K: Residents with sufficient incomes in right-to buy social 1,163 housing

L: Active elderly people living in pleasant retirement locations

M: Elderly reliant on state support

$\mathrm{N}$ : Young people renting flats in high density social housing

O: Families in low-rise social housing with high levels of benefit need

Total

SOURCE: UNDERSTANDING SOCIETY, 2015, WAVE 1, LINKED WITH 2001 CENSUS RURALURBAN CLASSIFICATION AND 2001 CENSUS OUTPUT AREA CLASSIFICATION, ACORN 2013 AND MOSAIC 2009. SAMPLE RESTRICTED TO ONE OBSERVATION PER ENUMERATED HOUSEHOLD.

respondents in England (E), owing to the ethnic minority boost sample, but less than 100 in Wales (W) and Scotland (S), and none in Northern Ireland (NI). The "City living" category is the smallest category in all countries. In empirical analyses, well-represented types may be broken up into its constituent groups and types with low frequencies may need to be treated as outliers. Figure 3 and Table 2 show the profile for Wave 1 responding adults by country.

However, the downside of both the Rural-urban classification and the OAC is that there has been considerable population growth in the $\mathrm{UK}$ since the 2001 Census, which means the classifications may not describe very well the neighbourhoods Understanding Society respondents lived in during 2009 to 2014 (Office for National Statistics, 2015).

\subsection{ACORN Classification}

Understanding Society provides the 2013 version of ACORN which was made available for academic research free of charge. Table 3 reports sample sizes using the 6-category version of the typology. Figure 4 and Table 3 show the profile for Wave 1 for responding adults by country.

Whilst providing similar cell sizes to OAC and qualitative information about the neighbourhoods, ACORN's principal advantage is that the neighbourhood 

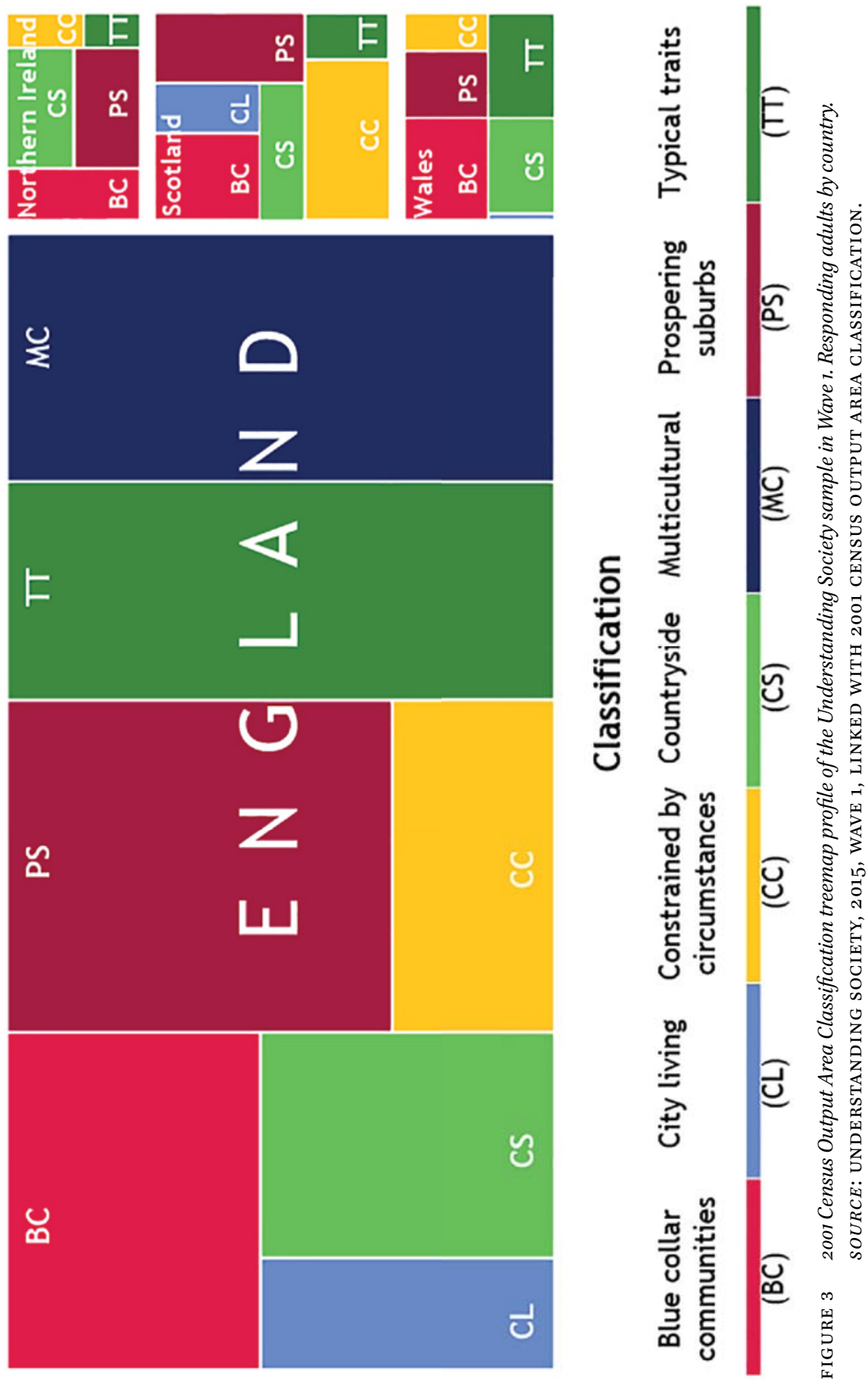
TABLE 22001 Census Output Area Classification profile of the Understanding Society sample in Wave 1, responding adults by country

\begin{tabular}{llllll}
\hline Census Output Area & England & Wales & Scotland & Northern & UK \\
Classification & (E) & (W) & (S) & $\begin{array}{l}\text { Ireland } \\
\text { (NI) }\end{array}$ &
\end{tabular}

\begin{tabular}{lrrrrr}
\hline $\begin{array}{l}\text { Blue collar } \\
\text { communities }\end{array}$ & 5,530 & 621 & 666 & 502 & 7,319 \\
$\begin{array}{lrrr}\text { City living } \\
\text { Countryside }\end{array}$ & 2,211 & 61 & 353 & 23 & 2,648 \\
Prospering suburbs & 4,253 & 440 & 388 & 560 & 5,641 \\
Constrained by & 8,039 & 372 & 734 & 543 & 9,688 \\
circumstances & 3,499 & 251 & 961 & 212 & 4,923 \\
$\begin{array}{l}\text { Typical traits } \\
\text { Multicultural }\end{array}$ & 7,636 & 472 & 276 & 157 & 8,541 \\
& 8,902 & 45 & 25 & n.d. & 8,972 \\
\end{tabular}

Note: Sample size calculation based on number of enumerated individuals that have a final interview outcome code of 1 "full interview".

SOURCE: UNDERSTANDING SOCIETY, 2015, WAVE 1, LINKED WITH 2001 CENSUS OUTPUT AREA CLASSIFICATION.

TABLE 32013 ACORN profile of the Understanding Society sample in Wave 1, number of responding adults by country

ACORN 6 category group England Wales Scotland Northern Ireland UK

\begin{tabular}{lrrrrr}
\hline Affluent Achievers & 8,315 & 326 & 679 & 334 & 9,654 \\
Rising Prosperity & 3,369 & 62 & 224 & 48 & 3,703 \\
Comfortable Communities & 10,736 & 784 & 716 & 887 & 13,123 \\
Financially Stretched & 8,896 & 807 & 1,037 & 485 & 11,225 \\
Urban Adversity & 8,596 & 279 & 724 & 234 & 9,833 \\
\hline
\end{tabular}

Note: The "Not in private households" category has been suppressed. Sample size calculation based on number of enumerated individuals that have a final interview outcome code of 1 "full interview".

SOURCE: UNDERSTANDING SOCIETY, 2015, WAVE 1, LINKED WITH 2013 ACORN CLASSIFICATION. 


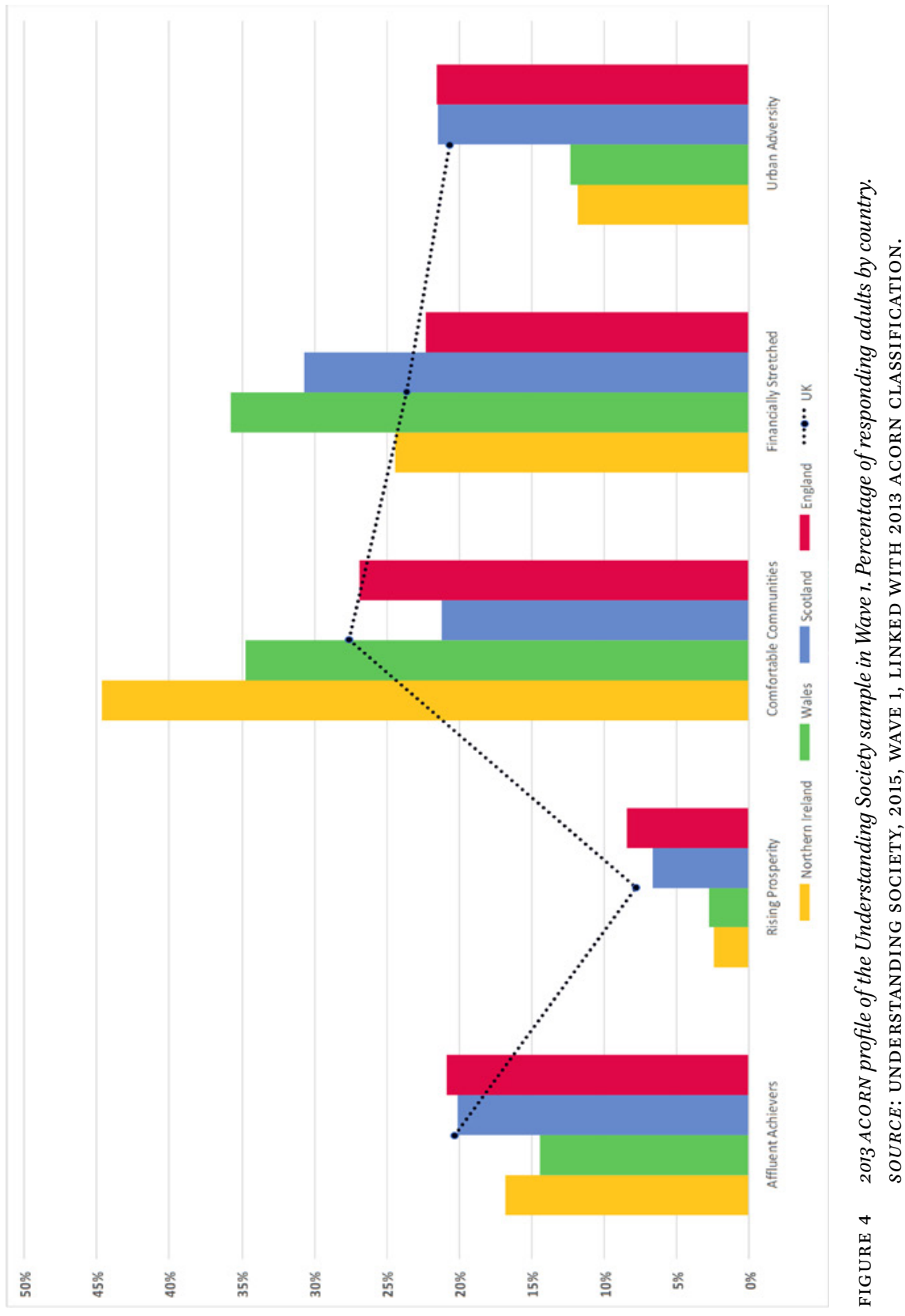


context can be measured annually. Thus, analysts do not have to assume that the neighbourhood context is fixed for the ten-year period between censuses. To exploit this feature, users would have to acquire the annual neighbourhood data and link it with Understanding Society using geographical identifiers such as the Census Lower Super Output Area (LSOA) code.

\subsection{MOSAIC Classification}

We have followed this LSOA linking approach using the MOSAIC UK 2009 typology of consumers. Area descriptions for 2004-2008 and 2010-2011 have been made available for research purposes free of charge.

To make the MOSAIC classification more comparable with OAC and ACORN, we aggregated the 67 types to 15 groups and calculated the dominant group in the neighbourhood. Figure 5 and Table 4 report sample sizes for responding adults by country and dominant group. Sample sizes for this analysis are much lower because we only had access to MOSAIC data for 2010 and 2011 and added the information to those respondents who were interviewed in the respective years. Effectively, this means we lose half of the Wave 1 and Wave 3 samples (i.e., those interviewed in 2009 and 2012) and we have no observations in Waves 4 and 5 . It can be seen that the number of observations in some types is well below 100 but would like to highlight that the classification does not require the data to be categorised in this way: the classification provides headcounts for all groups in the neighbourhood and can be used as continuous measures.

\subsection{Changes in Neighbourhood Context Across Time}

Finally, we looked at information over time. Figure 6 and Table 5 report the number of adults who provided interviews in waves 1 and 2, stratified by the characteristics of their neighbourhood in the first wave. The table reports the number of respondents whose neighbourhood contexts remained the same and the number and proportion for whom the neighbourhood context changed. For the rural-urban classification, OAC and ACORN change stems only from relocations; change in MOSAIC contexts stems from both relocations and changes in neighbourhood contexts. Results are reported for respondents who live in England in both waves. Sample sizes for the other U K countries will be significantly lower.

Overall, with respect to stability in neighbourhood contexts, cell sizes for all rural-urban areas in England remain above the 100 observations threshold with Hamlets and sparse urban areas dropping just below that threshold in some waves. Cell sizes for all OAC and ACORN groups are in the thousands, with the general patterns observed in the cross-sectional data replicated in the longitudinal sample. 


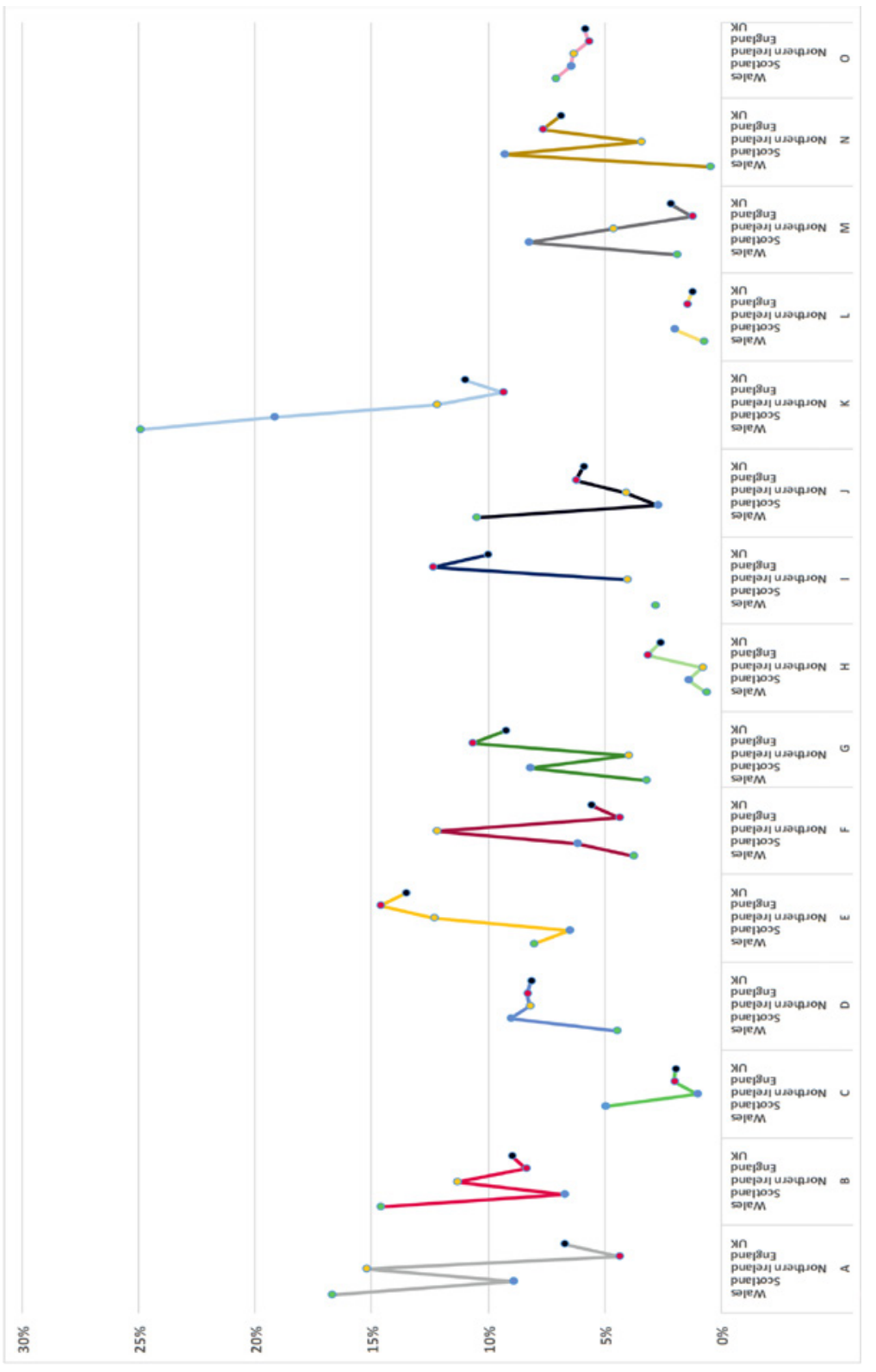

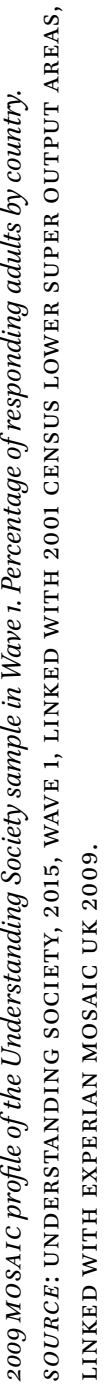

络 
TABLE 42009 MOSAIC profile of the Understanding Society sample in Wave 1, number of responding adults by country

MOSAIC group

England Wales Scotland Northern UK Ireland

A: Residents of isolated rural $870 \quad 183 \quad 140$ 569 1,762 communities

B: residents of small and mid$1,664 \quad 160 \quad 106$ 423 2,353 sized towns with strong local roots

C: Wealthy people living $396<5$ $<8$
-58

38 512 in the most sought-after neighbourhoods

D: Successful professionals living 1,649 $49 \quad 142$ 306 2,146 in suburban or semi-rural homes

E: Middle income families living 2,902

$88 \quad 102$

460

$3,55^{2}$ in moderate suburban semis

F: Couples with young chil865

41

455

1,458 dren in comfortable modern housing

G: Young, well-educated city 2,122 35

129

148 dwellers

$\mathrm{H}$ : Couples and singles in small $\begin{array}{lll}631 & 7 & 22\end{array}$ 30

690 modern starter homes

I: Lower income workers in ur-

2,454

3

ban terraces in often diverse areas

J: Owner occupiers in older$1,242 \quad 115$ style housing, typically in ex-industrial areas

$\mathrm{K}$ : Residents with sufficient $1,864 \quad 273$ 301 456 incomes in right-to buy social housing

L: Active elderly people living in 286 pleasant retirement locations

M: Elderly reliant on state $\begin{array}{llll}251 & 21 & 130 & 173\end{array}$ 326 support 
TABLE 42009 MOSAIC profile of the Understanding Society sample in Wave 1, number of responding adults by country (cont)

MOSAIC group

England Wales Scotland Northern UK

Ireland

\begin{tabular}{llrrrr}
\hline N: $\begin{array}{l}\text { Young people renting flats in } \\
\text { high density social housing }\end{array}$ & 5 & 146 & 128 & 1,804 \\
O: $\begin{array}{l}\text { Families in low-rise social hous- } 1,128 \\
\quad \begin{array}{l}\text { ing with high levels of benefit } \\
\text { need }\end{array}\end{array}$ & 78 & 101 & 236 & 1,543
\end{tabular}

Note: Sample size calculation based on number of enumerated individuals that have a final interview outcome code of 1 "full interview".

SOURCE: UNDERSTANDING SOCIETY, 2015, WAVE 1, LINKED WITH 2001 CENSUS LOWER SUPER OUTPUT AREAS, LINKED WITH EXPERIAN MOSAIC UK 2009.

How do rates of change vary when using different classifications? The taller the structure the more change detected between Wave 1 and 2.

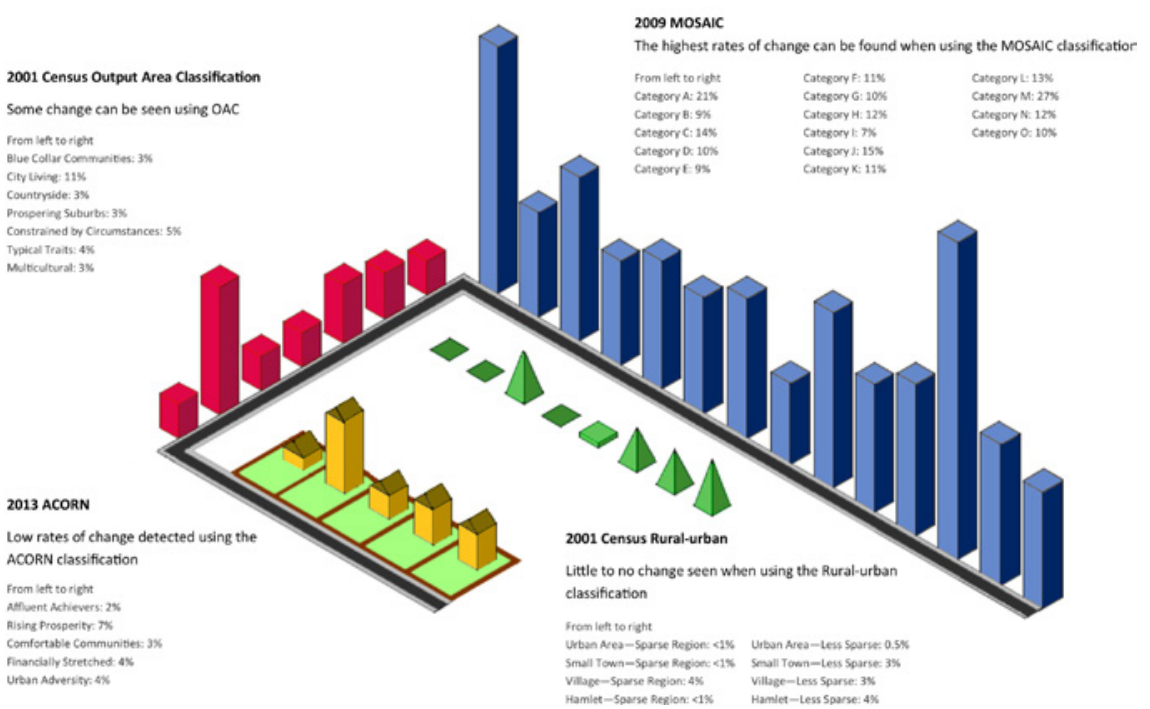

FIGURE 6 Wave-on-wave stability and change in neighbourhood characteristics for responding adults in Wave 1 and Wave 2.

SOURCE: UNDERSTANDING SOCIETY, 2015, WAVE 1-5 LINKED WITH 2001

CENSUS RURAL-URBAN CLASSIFICATION, 2001 CENSUS OUTPUT AREA

CLASSIFICATION, 2013 ACORN CLASSIFICATION AND 2009 MOSAIC UK. 
TABLE 5 Wave-on-wave stability and change in neighbourhood characteristics for responding adults in Wave 1 and Wave 2, number of observations

Neighbourhood type (Wave 1) Change?

No Yes $(\%)$

2001 Census Urban-rural classification

Urban area - sparse region

Small town - sparse region

Village - sparse region

Hamlet* - sparse region

Urban area less sparse

Small town less sparse

Village less sparse

Hamlet* - less sparse

$\begin{array}{rrl}97 & <5 & (-) \\ 147 & <5 & (-) \\ 129 & 6 & (4) \\ 74 & <5 & (-) \\ 23,899 & 112 & (<1) \\ 2,385 & 69 & (3) \\ 1,888 & 67 & (3) \\ 697 & 26 & (4)\end{array}$

2001 Census OAC

Blue collar communities

$4,110 \quad 146 \quad(3)$

City living

$1,281 \quad 160$

Countryside

$3,264 \quad 104$

Prospering suburbs

$6,247 \quad 163$

Constrained by circumstances

$2,503 \quad 120$

Typical traits

$5,589 \quad 236$

Multicultural

$5,504 \quad 176$

2013 ACORN

Affluent Achievers

$6,449 \quad 163 \quad(2)$

Rising Prosperity

$2,090 \quad 157 \quad(7)$

Comfortable Communities

$\begin{array}{lll}7,960 & 264 & (3)\end{array}$

Financially Stretched

$6,207 \quad 269 \quad(4)$

Urban Adversity

$5,663 \quad 266 \quad(4)$

2009 MOSAIC **

A: Residents of isolated rural communities

$\begin{array}{lll}548 & 147 \quad(21)\end{array}$

B: Residents of small and mid-sized towns with strong

$1,253 \quad 128 \quad(9)$ local roots

C: Wealthy people living in the most sought-after

$262 \quad 42 \quad(14)$ neighbourhoods 
TABLE 5 Wave-on-wave stability and change in neighbourhood characteristics for responding adults in Wave 1 and Wave 2, number of observations (cont)

Neighbourhood type (Wave 1)

Change?

No Yes

(\%)

D: Successful professionals living in suburban or semi-

$1,222 \quad 129 \quad(10)$ rural homes

E: Middle income families living in moderate suburban $\quad 2,071 \quad 193 \quad$ (9) semis

F: Couples with young children in comfortable modern $629 \quad 75 \quad(11)$ housing

G: Young, well-educated city dwellers

$\mathrm{H}$ : Couples and singles in small modern starter homes

$1,249 \quad 142 \quad(10)$

$\begin{array}{lll}437 & 57 \quad(12)\end{array}$

I: Lower income workers in urban terraces in often

$1,611 \quad 113 \quad(7)$
diverse areas

$\mathrm{J}$ : Owner occupiers in older-style housing, typically in $871 \quad 148 \quad(15)$ ex-industrial areas

K: Residents with sufficient incomes in right-to-buy social $1,345 \quad 166$ housing

L: Active elderly people living in pleasant retirement $196 \quad 28$ locations

M: Elderly reliant on state support

$\mathrm{N}$ : Young people renting flats in high density social housing

O: Families in low-rise social housing with high levels of $\quad 806 \quad 88$ benefit need

Notes: Basis is adults living in England and responding to Wave 1 and Wave 2. * Full label is Hamlet and Isolated Dwelling. ** The 2009 MOSAIC classification was only available for 2010 to 2011. Wave 1 to Wave 2 transitions therefore do not include respondents interviewed in 2009 (Wave 1 year 1 ).

SOURCE: UNDERSTANDING SOCIETY, 2015, WAVE 1-5 LINKED WITH 2001 CENSUS RURALURBAN CLASSIFICATION, 2001 CENSUS OUTPUT AREA CLASSIFICATION, 2013 ACORN CLASSIFICATION AND 2009 MOSAIC UK.

With respect to change, it can be seen that there is not very much change in neighbourhood characteristics from year to year. Although around $10 \%$ of the population move in any year, the neighbourhood contexts change for $0-5 \%$ of the sample when we consider the Rural-urban classification, with rates 
particularly low in the largest category. Seeing as many moves happen within the same Rural-urban type, the classification is not very good at picking up change. Rates are slightly higher for OAC $(3-11 \%)$ and ACORN $(2-7 \%)$. By contrast, levels of change in the MOSAIC dominant groups amount to $7-27 \%$. Note that the classification can also be used a lot more flexibly than presented here: analysts could, for example, look at change over time in the number of people of each of the 67 types and include this as continuous control variables in their neighbourhood effects models and changes can be separated into those stemming from moves versus those stemming from neighbourhood compositional changes.

\section{Conclusion}

Understanding Society provides a great many outcome and context variables for analyses of neighbourhood effects. The Study also provides access to a range of information about the neighbourhoods in which its members live, covering qualitative information that has already been linked and geographical identifiers that allow analysts to link their own neighbourhood data.

The analysis presented here describes respondents to the first five waves of Understanding Society in terms of the characteristics of their neighbourhoods. Four different neighbourhood classifications and their relative advantages have been described, and their strengths and weaknesses discussed. Our findings show that Understanding Society includes large numbers of observations in all types of neighbourhoods across all countries of the UK, and further captures people who move across different types of neighbourhoods. Linkage of longitudinal information about neighbourhoods allows analysts to disentangle the effects of relocations and neighbourhood change, making Understanding Society a powerful resource for neighbourhood effects research.

Finally, this paper can help users, and potential users, of Understanding Society make better informed choices about which classification to use to meet their own specific research question.

\section{Data}

- The Understanding Society data series is deposited at the U K Data Service - DoI:10.5255/UKDA-SN-6614-7

- Understanding Society: Waves 1-5, 2009-2014: Special Licence Access, Census 2001 
- Rural-Urban Indicators - DoI:10.5255/UKDA-SN-7454-3

- Output Area Classification - Do I:10.5255/UKDA-SN-6674-6

- Acorn Type 2013 - DoI:10.5255/UKDA-SN-7453-3

- Experian Demographic Data, 2004-2005 and 2008-2011 - DoI:10.5255/ UKDA-SN-5738-1

- Lower Layer Super Output Areas - DoI:10.5255/UKDA-SN-6670-6

- Temporal coverage: 2009-2015

Note that as this is prospective longitudinal study, data are updated annually. The hyphenated number at the end of the DOI denotes a specific version of data released. All changes to data made are documented in the DOI change log, but older versions are not made routinely available.

The process for applying to access SL data products is described in the Understanding Society data access strategy and applicants are guided through the process when they download the data from the UK Data Service website.

\section{Acknowledgements}

The work was supported by the Economic and Social Research Council (ESRC) through Understanding Society [grant number Es/Koo5146/1] at the University of Essex. Understanding Society is an initiative funded by the Economic and Social Research Council and various Government Departments, with scientific leadership by the Institute for Social and Economic Research, University of Essex, and survey delivery by the National Centre for Social Research and TNS вмгв. Figure 1 was designed by Ricardo Pinto. Infographics have been compiled by Simon Parker of the U Nata Service.

\section{References}

Burgess, S., Gardiner, K., \& Propper, C. (2006). School, Family and County Effects on Adolescents' Later Life Chances. Journal of Family and Economic Issues, 27(2), 155-184. CACI Limited (2014). The ACORN User Guide - The Consumer Classification. London: www.acorn.caci.co.uk/downloads/Acorn-User-guide.pdf.

Culliney, M. (2016). Escaping the rural pay penalty: location, migration and the labour market. Work, Employment \& Society. doi:10.1177/0950017016640685.

Dietz, R. D. (2002). The estimation of neighborhood effects in the social sciences: An interdisciplinary approach. Social Science Research, 31(4), 539-575. 
Experian Limited. (2009). Experian's Mosaic Public Sector citizen classification for the United Kingdom. www.esds.ac.uk/doc/5738/mrdoc/pdf/5738_mosaicpublicsector_info_2010.pdf.

Friedrichs, J., Galster, G. C., \& Musterd, S. (2003). Neighbourhood effects on social opportunities: The European and American research and policy context. Housing Studies, $18(6)$, 797-806.

Galster, G. C. (2008). Quantifying the effect of neighbourhood on individuals: Challenges, alternative approaches and promising directions. Journal of Applied Social Sciences Studies, 128(1), 7-48.

Knies, G. (2015). Understanding Society - UK Household Longitudinal Study: Wave 1-5, 2009-2014, User Manual (5 ed. Vol. 1). Colchester: University of Essex.

Knies, G., Burgess, S., \& Propper, C. (2008). Keeping up with the Schmidts: An empirical test of relative deprivation theory in the neighbourhood context. Journal of Applied Social Sciences Studies, 1(2008).

Knies, G., Nandi, A., \& Platt, L. (2016). Life satisfaction, ethnicity and neighbourhoods: Is there an effect of neighbourhood ethnic composition on life satisfaction? Social Science Research (6o:110-124), doi:10.1016/j.ssresearch.2016.01.010.

Lynn, P. L., \& Knies, G. (2015). Understanding Society Quality Profile. In P. L. Lynn \& G. Knies (Eds.), Understanding Society Quality Profile (Vol. 1). Colchester: ISER University of Essex.

Musterd, S., \& Andersson, R. (2006). Employment, social mobility and neighbourhood effects: The case of Sweden. International Journal of Urban and Regional Research, $30(1), 120-140$.

Office for National Statistics. (2015, 25 June 2015). Mid-year population estimates for the UK 2014. Population estimates Retrieved 11 October, 2016.

Office for National Statistics. (2016a). 2001 area classifications. http://webarchive .nationalarchives.gov.uk/20160105160709/http://www.ons.gov.uk/ons/guide-method/geography/products/area-classifications/ns-area-classifications/index/index .html.

Office for National Statistics. (2016b). 2001 Rural-urban classification. http://webarchive.nationalarchives.gov.uk/20160105160709/http://www.ons.gov.uk/ons/guidemethod/geography/products/area-classifications/rural-urban-definition-and-la/ index.html.

Overman, H. G. (2002). Neighbourhood effects in large and small neighbourhoods. Urban Studies, 39(1), 117-130.

Plum, A., \& Knies, G. (2015). Does Neighbourhood Unemployment Affect the Springboard Effect of Low Pay? ISER Working Paper, 11/2015.

Propper, C., Jones, K., Bolster, A., Burgess, S., Johnston, R., \& Sarker, R. (2005). Local neighbourhood and mental health: Evidence from the uK. Social Science \& Medicine, $61(10), 2065^{-2083}$. 
Shields, M. A., Price, S. W., \& Wooden, M. (2009). Life satisfaction and the economic and social characteristics of neighbourhoods. Journal of Population Economics, $22(2), 421-443$.

University of Essex. Institute for Social and Economic Research. (2010). British Household Panel Survey: Waves 1-18, 1991-2009 [computer file]. 18th Edition. U K Data Service. SN: 5151, 10.5255/UKDA-SN-5151-1.

University of Essex. Institute for Social and Economic Research (2015a). Understanding Society: Waves 1-5, 2009-2014. [data collection]. 7th Edition. U K Data Service. SN: $6614,10.5255 /$ UKDA-SN-6614-7. 